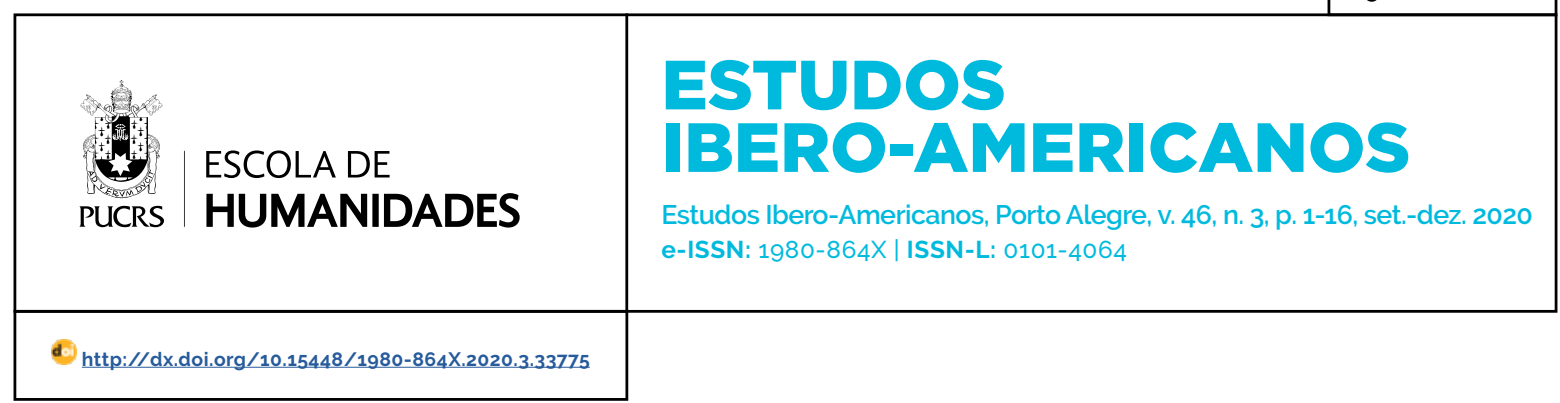

SEÇÃO LIVRE

\title{
Sexualidade subversiva e performatização dos gêneros a partir dos processos inquisitoriais de Violante Carneiro e Margarida Carneiro
}

\author{
Subversive sexuality and performativity of gender from the inquisitorial processes \\ Violante Carneiro and Margarida Carneiro \\ Sexualidad subversiva y la performatización de los géneros a partir de los procesos \\ inquisitoriales de Violante Carneiro y Margarida Carneiro
}

\author{
Marcus Vinicius Reis ${ }^{1}$ \\ orcid.org/0000-0002-5972-1289 \\ marcus.reis@unifesspa.edu.br
}

Recebido em: 31/3/2019

Aprovado em: 12/9/2019.

Publicado em: 21/12/2020.
Resumo: Em conjunturas desfavoráveis, marcadas pela vigência de um sistema patriarcal e misógino, o interesse em contar com o sobrenatural representou para algumas mulheres uma importante ferramenta de resposta a esse contexto normativo. O universo das relações sociais, o interesse em controlar as vontades de outrem para a realização de enlaces amorosos, incluindo casamentos ou mesmo a salvação das vidas conjugais, foram registrados na documentação inquisitorial, ainda mais quando estiveram associados ao protagonismo almejado pelas mulheres. Este trabalho busca, portanto, investigar, à luz das relações de gênero, as trajetórias de Violante Carneiro e Margarida Carneiro, processadas pelas autoridades da visitação inquisitorial realizada na América portuguesa (1591-1595). Pretende-se, assim, investigar como a sexualidade serviu para essas mulheres como ferramenta de subversão, em que práticas mágico-religiosas foram utilizadas como meio para alcançar autonomia em suas vidas.

Palavras-chave: Inquisição portuguesa. Gênero. Sexualidade. Práticas mágico-religiosas.

Abstract: In unfavorable situations, marked by the validity of a patriarchal and misogynist system, the interest in counting on the supernatural represented for some women an important tool to respond to this normative context. The universe of relationships, the interest in controlling the wills of others for the realization of love bonds, including marriages or even the salvation of conjugal lives, were recorded in various inquisitorial processes. The fluidity of sexuality was, in turn, an aspect that caught the attention of the authorities, especially when it was associated with the protagonism sought by women. This work seeks, therefore, to investigate, in the light of gender relations, the trajectories of Violante Carneiro and Margarida Carneiro, processed by the authorities of the inquisitorial visitation in Portuguese America (1591-1595).

Keywords: Portuguese Inquisition. Gender. Sexuality. Witchcraft.

Resumen: En coyunturas desfavorables, marcadas por la vigencia de un sistema patriarcal y misógino, el interés en contar con lo sobrenatural representó para algunas mujeres una importante herramienta de respuesta a ese contexto normativo. El universo de las relaciones, el interés en controlar las voluntades de otro para la realización de enlaces amorosos, como bodas o incluso la salvación de las vidas conyugales, se registraron en diversos procesos inquisitoriales. La fluidez en la sexualidad fue, a su vez, aspecto que llamó la atención de las autoridades, aún más cuando estuvo asociada al protagonismo anhelado por las mujeres. Este documento busca, por lo tanto, investigar, a la luz de las relaciones de género, las trayectorias de Violante Carneiro y Margarida Carneiro, procesadas por las autoridades de la visita inquisitorial celebradas en la América portuguesa (1591-1595).

Palabras clave: Inquisición portuguesa. Género. La sexualidad. Prácticas mágico-religiosas. 


\section{Introdução}

O fato de Violante Carneiro ser filha de Margarida Carneiro não é o único motivo que justifica o interesse em analisar em conjunto os seus processos inquisitoriais no presente trabalho, tampouco o fato das suas trajetórias terem se cruzado com a Primeira Visitação do Santo Ofício, realizada nas capitanias do Nordeste (Bahia e Pernambuco), entre os anos de 1591 e 1595. A motivação que sustentou as investigações realizadas por Heitor Furtado de Mendonça, responsável por esse episódio, constitui um primeiro aspecto que viabiliza essa relação, já que ambas foram processadas por terem se utilizado, durante alguns atos sexuais, de elementos pertencentes à sacralidade católica, tornando-os partes essenciais das práticas mágico-religiosas que teriam realizado. A existência de uma heterossexualidade compulsória, ${ }^{2}$ produzida e prescrita em prol da reafirmação de uma estrutura binária (masculino/ feminino), em que sexo e desejo são atrelados diretamente a uma matriz heterossexual (BUTLER, 2016, p. 53), também aproxima ambas as trajetórias. Isto é, mãe e filha inseriram-se em um espaço amplamente silenciado no mundo português: a sexualidade vivenciada pelas mulheres.

Segundo Judith Butler (2016, p. 38-39), as relações sociais são pautadas por uma "heterossexualização do desejo", ou seja, é a partir de uma posição masculina e heterossexual que a vida social é regulada, prevalecendo o interesse em produzir "oposições discriminadas e assimétricas entre 'feminino' e 'masculino', em que estes são compreendidos como atributos expressivos de 'macho' e de 'fêmea'". Esse binarismo, considerando o mundo português, se tornou hegemônico na medida em que foi consolidada a noção de uma sexualidade feminina pautada na inferiorização das mulheres, quando comparada aos homens. Por isso que, embora comum aos homens e às mulheres, o orgasmo nesse período foi, com base nos aspectos anatômicos e reprodutivos, hierarquicamente definido. O prazer do homem condicionava a natureza do prazer que a mulher possuiria, ainda que fosse consensual por parte dos tratadistas que o orgasmo feminino era mais duradouro (LAQUEUR, 2001, p. 64).

Em a Imagem da vida cristã (1958), é evidente a lógica moralista pautada por essa matriz heterossexual, sendo um aspecto recorrente na literatura religiosa portuguesa do século XVI. Escrita pelo frade Heitor Pinto, esse tratado pode ser entendido a partir do interesse do autor em reafirmar as hierarquias existentes entre homens e mulheres no âmbito do casamento e como essa condição era encarada como fator primordial para a existência de um ordenamento que não colocasse em xeque a vida política e religiosa portuguesa:

\begin{abstract}
Verdade é que, ainda que a mulher quanto ao matrimónio seja igual ao marido, contudo, no que toca à disposição e governação da casa e fazenda, o marido é a cabeça da mulher, como o diz S. Paulo na Primeira aos Corintios. Que a mulher deva ser subjeta ao marido, dizem-no S. Jerónimo sobre a Espistola a Tito, Santo Agostinho no livro das Questões do Génesis, Santo Ambrósio no Hexamerão [...] mas não como escrava, senão como companheira: não será sujeição servil, mas social. A mulher não há de dominar sobre marido: por isso não foi formada da cabeça de Adão: nem deve ser desprezada dele como escrava: por isso não foi formada dos pés: mas há de ser companheira do marido: por isso foi formada da costa, que está no meio do corpo. [...] os quais todos afirmam que a mulher deve guardar ao marido grande lealdade, e ser-lhe subjeita: e honrada dele como companheira: e que ambos se hão de ter grande amor um ao outro (PINTO, 1958, p. 38).
\end{abstract}

Como consequência dessa oposição e da naturalização do binarismo citado a partir de obras como a do frade Heitor Pinto, que é tornada visivel a existência de uma hierarquia social pautada na diferenciação do sexo, em que a "matriz cultural por meio da qual a identidade de gênero se torna inteligivel" exige, segundo Butler (2016, p. 44), o silenciamento de algumas identidades de modo que a heterossexualidade seja a matriz capaz de definir as relações sociais.

\footnotetext{
2 É importante sublinhar que a noção de "heterossexualidade compulsória", embora tenha sido amplamente discutida por Judith Butler. foi pensada a partir do ensaio de Adrienne Rich, intitulado Heterossexualidade compulsória e existência lésbica (1980), cuja tradução brasileira foi realizada em 2012. Para a autora, trata-se não apenas de um fenômeno visivel nas sociedades, mas, igualmente, uma ideologia $(\mathrm{RICH}, 2012$, p. 23). Por fim, destaca-se que a própria Judith Butler (2016, p. 258), em Problemas de gênero, informou que a sua noção de "heterossexualidade compulsória" foi influenciada pelos pressupostos de Monique Wittig - muito por conta da ideia de que existe um "contrato heterossexual" - e de Adrienne Rich.
} 
O presente trabalho defende, portanto, a existência de padrões de masculinidade e feminilidade que foram construidos e difundidos a partir de uma moralidade católica e de uma legislação régia, sendo prescritos aos homens e às mulheres no mundo português como forma de alcançar coesão social e consolidação de hierarquias pautadas na divisão citada. As análises que se seguem partirão, assim, do interesse em compreender como esses padrões foram construidos e quais os símbolos culturais que evocaram os papéis sociais masculinos e femininos naquele contexto. É importante salientar, ainda, que a construção da análise parte do entendimento de que esse processo se constitui historicamente e em conformidade com os interesses normativos em jogo (SCOTT, 1995, p. 86). Por outro lado, compreendendo o gênero como uma identidade subjetiva, uma vez que, nem sempre, os homens e as mulheres cumpriram fidedignamente os papéis sociais destinados a eles (SCOTT, 1995, p. 87-88), este trabalho pretende refletir sobre como a sexualidade tornou-se uma importante ferramenta de subversão por parte das mulheres, ainda mais quando as práticas mágico-religiosas estiveram em cena. Para isso, os processos inquisitoriais de Violante Carneiro e de sua mãe, Margarida Carneiro, serão a base principal para as discussões e reflexões desenvolvidas ao longo deste artigo.

\section{O retrato da sexualidade na América portuguesa a partir da historiografia}

Com o interesse voltado amplamente para os relatos promovidos durante a Primeira Visitação, Lígia Bellini (2014) trouxe ao universo dos estudos inquisitoriais brasileiros uma notável contribuição a respeito do modo como o Santo Ofício buscou lidar com as relações sexuais e afetivas protagonizadas pelas mulheres. Foi seu interesse investigar até que ponto as práticas cotidianas das mulheres na América portuguesa foram consoantes ao previsto em tratados morais e religiosos, ou seja, toda uma literatura normativa existente à época. Através desse percurso, a autora compreendeu a trajetória de Paula de Sequeira, processada durante essa visitação, como um dos principais exemplos de mulheres que estiveram distantes dos modelos de regulação social vigentes à época e, mais ainda, encontraram na sexualidade fluida um espaço de construção de autonomias diante das normatizações vigentes.

Mesmo casada com o Contador da Fazenda D'El Rei, era costume de Paula de Sequeira, "fascinada como era pela novidade, [...] lançar-se com ousadia às aventuras que the oferecia a vida mais ou menos pacata na sede da colônia" (BELLINI, 2014, p. 21). E foi o que a cristã-velha fez ao não mais resistir às investidas amorosas de Felipa de Souza, realizadas ao longo de dois anos. Em sua própria confissão, reafirmou a denúncia feita pelo clérigo Balthasar de Miranda, que havia informado ao visitador acerca das relações carnais entre a confessante e Felipa:

[...] ela própria procurou o Santo Ofício e contou sobre seu "caso" com Felipa de Souza, que havia começado dois anos antes 'com muitas cartas de amores e requebros' e presentes que Felipa the mandava, o qual teve o seu desfecho no dia em que a recebeu em sua casa e 'ambas tiveram ajuntamento carnal hua com a outra" (BELLINI, 2014, p. 22).

No mais, ainda foi acusada por se relacionar com algumas feiticeiras que circulavam pelas ruas de Salvador, como Isabel Rodrigues - conhecida pela alcunha de "Boca-torta". Diante do iminente escândalo social e do interesse por parte do visitador em fazer valer não somente o Monitório ${ }^{3}$ afixado desde sua chegada, mas, também, o combate a quaisquer desvios pertencentes ao universo inquisitorial, Paula de Sequeira não se livrou do processo e de algumas penitências: "[...] seis dias de prisão, duas aparições públicas como ré do Santo Ofício, o pagamento da alta quantia de 50 cruzados, além de penas espirituais e abjuração na casa do Inquisidor" (BELLINI, 2014, p. 22).

Quanto a Felipa de Souza, a sua trajetória é ainda mais rica, já que a mesma foi mencionada nas denúncias ao visitador por supostamente manter uma "nefanda amizade" com ao menos

\footnotetext{
3 De acordo com Elias Lipiner (1997, p. 101), trata-se de uma "lista desenvolvida dos fatos considerados delituosos pela Inquisição e dos indícios de judaismo, destinada a esclarecer as culpas próprias a serem confessadas ou as alheias a serem denunciadas".
} 
seis mulheres. Como afirmou a autora, através de "cartas, presentes, 'requebros', 'palavras lascivas' e outros expedientes, Felipa procurou aproximar-se das mulheres que despertavam nela 'grande amor e afeição carnal', segundo seu próprio depoimento" (BELLINI, 2014, p. 23). Comparadas às práticas eróticas de Violante e Margarida Carneiro, nas quais as práticas mágico-religiosas foram o instrumento primordial para a sustentação dos seus afetos, mesmo que efêmeros, as relações de Felipa foram baseadas na sedução prática, como quando ia à missa trocar gracejos com uma vizinha. Ainda assim, prevaleceu a mesma sacralidade em torno da sexualidade, na medida em que Felipa utilizou a igreja como espaço para a realização desses atos. Seu processo foi estabelecido no mesmo período em que Paula de Sequeira foi processada. Felipa de Souza, no entanto, foi quem sofreu as maiores punições, incluindo penitências espirituais, açoites públicos e, por fim, o degredo. É possivel que a prevalência de uma posição ativa nas conquistas amorosas, incentivando algumas mulheres a se relacionarem consigo, tenha agravado a situação de Felipa de Souza diante das autoridades da visitação.

O universo das sexualidades referente à América portuguesa não foi analisado pela historiografia brasileira somente no âmbito das práticas sexuais e amorosas entre as mulheres. Por essa razão, cabe destacar as análises empreendidas por Gilberto Freyre e a sua validade ainda nos dias atuais, antes mesmo do trabalho de Ligia Bellini.

Entre as mulheres indigenas, o autor destacou a maior facilidade que elas encontraram frente a esse universo, sejam como concubinas ou cozinheiras, no qual puderam "exprimir-se em atividades agradáveis ao seu sexo e à sua tendência para a estabilidade" (FREYRE, 2006, p. 108). Por sua vez, também discutiu o suposto caráter sádico que acompanhou a formação social brasileira: "a verdade, porém, é que nós é que fomos os sadistas"4. A casa-grande, por sinal, foi um importante espaço de profusão da vida sexual e de um "patriarcalismo polígamo"
(FREYRE, 2006, p. 18). Tamanha diversidade das práticas sexuais obteve destaque nas análises do autor a partir da documentação decorrente das atuações empreendidas pelos representantes do Santo Ofício desde os Quinhentos:

[...] homens casados casando-se outra vez com
mulatas, outros pecando contra a natureza
com efebos da terra ou da Guiné, ainda ou-
tros cometendo com mulheres a torpeza que
em moderna linguagem científica se chama,
como nos livros clássicos, felação, e que nas
denúncias vem descrita com todos osfferr;
desbocados jurando pelo 'pentelho da Virgem'
[...] (FREYRE, 2006, p. 23).

Considerado pela teologia católica como um mal necessário, tendo em vista a existência das práticas sexuais, o casamento foi introduzido na Igreja como tentativa de disciplinamento das consciências, ao mesmo tempo em que buscou estabelecer hierarquias e normas sociais a serem seguidas por homens e mulheres. Nesse processo, o sexo passou a ser defendido pelas autoridades religiosas apenas sob a lógica reprodutora, afastando o desejo e o prazer desse universo, pois era entendimento de que ambos não pertenciam ao "eixo da moral cristã desde a pregação apostólica" (VAINFAS, 1986, p. 59). Essa afirmação, retirada das análises de Ronaldo Vainfas, buscou sintetizar a preocupação que permeou os representantes do catolicismo desde meados do século XII em delimitar um equilibrio entre casamento e sexo. A luxúria passou a ser definida como o grande pecado representante das transgressões carnais e como uma das principais problemáticas que impediam a manifestação do matrimônio.

Foi em 1540, quando esteve no Porto, que João de Barros escreveu sua principal obra, Espelho de Casados, sendo editada ao longo dos séculos XVI e XVII - tamanha importância adquirida. Em linhas gerais, essa obra pode ser entendida como uma ampla defesa do matrimônio, inserida em um contexto cuja valorização desse sacramento ganhou novo sentido e maior defesa por parte das autoridades religiosas, influenciadas pelo Concilio de Trento. Ainda que não possuísse formação

\footnotetext{
4 Afirmação que buscou rebater as assertivas de Nina Rodrigues e José Veríssimo, defensores da ideia de que, aos descendentes de escravos, caberia a maior propensão aos desvios sexuais. Cf. FREYRE, 2006, p. 247.
} 
religiosa, a presença do doutor ${ }^{5}$ em meio a esse tipo de literatura moralista constitui importante evidência de como a normatização dos corpos femininos assumiu uma política também presente nas monarquias do período, por se tratar de uma forma eficiente de regulação social.

Mesmo prevalecendo a defesa do casamento como ato sacramental a ser seguido por homens e mulheres, encarando-o como alicerce de uma ordem social compativel com os ideais civis e religiosos, a obra de João de Barros não escapa à estrutura narrativa de grande parte dos discursos da época, em que um determinado modelo de mulher foi idealizado. Por isso a prevalência de sete tópicos, dos 12 existentes no seu trabalho, com relação aos elementos que possibilitariam um bom casamento. Nesses tópicos, é visivel como esse modelo foi pensado pelo autor - vide exemplo do seu debate em torno da virgindade, defendendo-a como condição obrigatória para as mulheres alcançarem uma relação bem-sucedida. Há, também, a defesa da importância de as mulheres possuírem dote, já que "sem os bens da fortuna não acontece a bem-aventurança" (NORONHA; CABRAL, 1624. p. LVII). O mesmo peso é dado pelo autor à fama pública a respeito da futura cônjuge:

que seja com vizinha conhecida filha de seu vizinho e natural, porque como diz o proverbio: a mulher e a vaca busca traz a casa. O vizinho conhece e sabe os defeitos de seu vizinho, e conhece os costumes e manhas de sua filha e a estranha que nunca viu as vezes é mui diferente do que ele deseja e do que lhe compraz (NORONHA; CABRAL, 1624, p. LIX).

No entanto, afora os círculos sociais defensores dessa moralidade atrelada a um padrão de feminilidade normativo, cujo interesse era o de normatizar os corpos e a sexualidade dos individuos, as arestas permaneceram entre boa parte da população.

Publicado em 1988, O Sexo Proibido, de Luiz Mott, é considerado pelo autor como a "primeira tentativa de sistematização dos documentos relativos aos crimes sexuais e heresias morais perseguidos pelo Santo Ofício em Portugal e no Brasil" (MOTT, 1988, p. 12). Diante desse trabalho de reunião de fontes, atrelado ao objetivo de investigar os mecanismos de repressão utilizados pelo Santo Ofício no domínio da sexualidade, o autor percorreu o universo das práticas sexuais entre os africanos, em um primeiro momento, partindo, em seguida, para o universo homossexual na América portuguesa - "pecado que os Inquisidores consideravam tão feio, sujo e desonesto, que até o Diabo fugia quando o via ser praticado" (MOTT, 1988, p. 14). Por fim, analisou o debate em torno da virgindade de Nossa Senhora, "um dos mitos mais sagrados e polêmicos do catolicismo".

Chama a atenção, por exemplo, os diversos relatos trazidos pelo autor referentes ao pecado nefando, em que vários homens foram acusados frente às autoridades religiosas por praticarem esse ato com as suas esposas e, mais ainda, com as escravas. Vide a acusação de Ana Maria contra seu marido Jacinto da Costa que, segundo Luiz Mott (1988, p. 55), disse que seu cônjuge a teria obrigado a praticar tal delito, "chegando a dizer-lhe: "que era casado e tinha liberdade de usar das duas vias...". Já no Rio de Janeiro, uma escrava de nome Clara chegou a denunciar o seu proprietário, Manuel Nunes Pelouro, de "forçá-la a atos de sodomia: levantando-lhes as roupas, lhe dizia que sendo sua cativa o havia de servir em tudo'" (MOTT, 1988, p. 55). Todavia, ainda que de forma mais tímida, alguns autores também identificaram o outro lado desse âmbito das práticas sexuais, em que não somente essa dominação patriarcal prevaleceu.

Na obra Trópico dos pecados (2010), Ronaldo Vainfas também investigou as moralidades e os desvios sexuais presentes na América portuguesa, amplamente inseridos no universo de atuação inquisitorial neste espaço. Comparado ao trabalho de Luiz Mott, o seu objeto de estudo não residiu somente nas práticas sexuais entre os escravos. Destacou, assim, a presença das "mulheres nefandas" ou, em outras palavras, as mulheres que optaram de forma consciente em se relacionarem 
sexual e amorosamente com outras mulheres, embora a maioria das relações, segundo o autor, não tenham ultrapassado o campo dos "experimentos de moçoilas recém-saidas da puberdade, pertencentes aos mais variados segmentos da sociedade colonial" (VAINFAS, 2010, p. 230).

Inserida em um contexto de produção historiográfica interessada em articular o gênero às práticas sociais das mulheres inseridas nesse mesmo recorte, Júnia Furtado (2003, p. 19) pretendeu compreender quem, de fato, teria sido Chica da Silva: se representou a figura da "bruxa, sedutora, heroína, rainha ou escrava". O pano de fundo dessa proposta correspondeu ao objetivo da autora em "lançar luz sobre as demais muIheres daquele periodo, inserindo-as na história" (FURTADO, 2003, p. 19).

Nascida entre os anos de 1731 e 1735, filha de uma escrava e de um homem branco, Chica da Silva alcançou a condição de forra por volta de 1754. Júnia Furtado, em linhas gerais, percebeu o interesse evidente de Chica da Silva em definir uma identidade capaz de afastá-la desse passado escravocrata a partir da adoção dos sobrenomes "Silva" e "Oliveira". Somada a essa atitude, a mesma Chica da Silva levou adiante essa nova vida junto a João Fernandes de Oliveira, o seu último proprietário, responsável por sua alforria e importante figura pertencente ao contexto diamantino em Minas Gerais. Além disso, a autora percebeu o visivel interesse de Chica da Silva em tornar-se praticamente uma Dona, reproduzindo costumes pertencentes ao universo das senhoras de sua época, como a sua recusa à amamentação dos seus filhos.

Nas palavras de Júnia Furtado, Chica da Silva se tornou uma verdadeira "Senhora do Tejuco", levando adiante uma série de costumes caracteristicos das damas da época, incluindo o uso de vestimentas luxuosas pelos diversos espaços em que circulava. A sua trajetória é representativa de como foi recorrente a relação de algumas mulheres forras com as riquezas provenientes do distrito diamantino, externando-as principalmente no vestuário e nas joias. Não bastasse isso, Chica da Silva também adquiriu proeminência por conter um plantel significativo de escravos, o que lhe serviu, por sua vez, como ferramenta de inserção em uma sociedade marcadamente caracterizada por hierarquias sociais pautadas pelo "mundo dos livres". No mais, a sua preocupação com a educação das filhas fez com que as internasse em um convento, o das Macaúbas, de modo que fosse ofertada uma instrução formal capaz de conferir virtudes às suas herdeiras.

A partir de suas pesquisas, a autora compreendeu que a história da região diamantina, recorte espacial de suas análises, esteve relacionada à presença das negras e mulatas forras que, "poderosas, como Chica da Silva, submetiam os homens brancos a seus desejos" (FURTADO, 2003, p. 107). Mais precisamente, argumentou que, nas Minas Gerais, gênero e raça foram conceitos interseccionais, sendo Chica da Silva um dos maiores exemplos dessa relação e de como essa interação se deu, cujo "sexo foi determinante nas condições mais ou menos facilitadas de acesso à alforria" (FURTADO, 2003, p. 109). Todos esses elementos, enfim, sustentaram a conclusão de Furtado, destacando que o percurso construído por Chica da Silva ao longo de sua trajetória pertenceu a uma condição paradoxal vivenciada por diversas mulheres quando interessadas em retomar o controle de suas vidas, ainda que o passado de escravas fosse explícito. Por isso, conforme ressaltou a autora, muitas dessas mulheres reproduziram até mesmo uma série de padrões de comportamento elitistas, de modo a ampliar suas participações nos espaços em que estavam inseridas.

Em meio aos estudos mais atuais voltados ao campo da sexualidade, destaca-se o trabalho de Cássio Rocha, igualmente focado na América portuguesa do século XVI. Em seu Masculinidades e Inquisição (2016), o autor resgatou a documentação resultante da Primeira Visitação, de modo a problematizar os padrões de masculinidade hegemônicos no periodo, ao mesmo tempo em que se debruçou sobre as práticas cotidianas a fim de discutir esse processo.

Voltado a uma vertente influenciada pelos pressupostos de Michel Foucault, nos quais é questionada a ideia de se pensar a existência humana - e a sexualidade, claro - sob uma dimensão essencialmente natural, interessou ao autor investigar 
os mecanismos, discursos e relações de poder sustentadores das masculinidades nesse espaço. "Ser homem", ou os significados por detrás dessa construção, foi a problemática central de sua obra, fazendo-o adentrar no campo das sexualidades como o caminho privilegiado para levar adiante essa proposta. Utilizando-se da categoria de gênero, referenciando, também, os trabalhos de Judith Butler, as suas análises percorreram trajetórias de homens e mulheres acusados ao longo dessa Visitação, tratando-os como exemplos da performatização dos gêneros para além das estruturas e dispositivos vigentes. Com a sua pesquisa, o autor defendeu a descontinuidade das categorias de "homem", "mulher" e "homossexual", preocupando-se, por sua vez, com as realidades históricas e discursivas pertencentes às suas construções. Uma das maiores contribuições das discussões realizadas em seu trabalho consistiu na análise da trajetória de Frutuoso Álvares.

Ressalta-se que o autor não foi o primeiro a tratar diretamente da trajetória desse clérigo, uma ressalva destacada também em seu trabalho, já que foram referenciadas as obras de Rodolpho Garcia (1929 apud ROCHA, 2016, p. 151). A trajetória de Frutuoso Álvares também foi foco de investigação para Luiz Mott (2010, p. 23) e Ronaldo Vainfas (2010), autores igualmente interessados em analisar o processo estabelecido contra o mesmo vigário de Matoim, já no período em que residia na Capitania da Bahia. Nas palavras de Vainfas (2010, p. 172), o padre Frutuoso Álvares "era um antigo e 'clássico' fanchono que há décadas cometia atos sodomíticos", não sendo inédito, portanto, o número de denúncias, bem como o processo que o visitador estabeleceu a fim de investigar tais práticas.

Ainda assim, o processo de Frutuoso Álvares ganha, nas análises de Cássio Rocha, novos contornos por conta do seu interesse em instrumentalizar os conceitos caros às teóricas do gênero, como a noção de "performatividade de gênero", de Judith Butler (2016, p. 201). Rocha também concluiu que, embora eivado de práticas homoeróticas presentes desde o tempo em que morava em Portugal, prevaleceu no clérigo um perfil essencialmente voltado aos padrões hegemônicos de masculinidade. Por fim, afirmou que os pecados atrelados ao vigário e por ele confessados, foram mais direcionados aos desvios morais do que à reafirmação de uma identidade sexual (ROCHA, 2016, p. 188).

Os imaginários, bem como as práticas sociais pertencentes ao universo da América portuguesa e analisadas pelos autores referenciados acima, possibilitam compreender a existência de uma longa duração envolvendo a construção dos papéis sociais endereçados às mulheres e eivados de uma ambiguidade que acompanhou as mesmas ao longo do século XVI. Trata-se de uma percepção importante não apenas para analisar como os discursos e estruturas normativas foram consolidadas ao longo dos séculos. Vale sublinhar que, nem sempre, esse roteiro foi seguido à risca pelos indivíduos, revelando consideráveis arestas produzidas conscientemente por algumas mulheres, em que a sexualidade foi um dos importantes palcos dessa transgressão. Associado ao sobrenatural, esse palco também adquiriu proeminência, como será possivel identificar nas trajetórias de Violante Carneiro e Margarida Carneiro.

\section{Sacralidade católica e sexualidade subvertida a partir dos processos de Violante Carneiro e Margarida Carneiro}

É importante destacar que Violante e Margarida Carneiro já haviam passado pela mesa da visitação por conta das denúncias que ambas realizaram no contexto do processo inquisitorial estabelecido por Heitor Furtado de Mendonça contra Maria Gonçalves, apontada em seu processo como sendo a mais importante feiticeira na região de Salvador. No entender de Margarida Carneiro, o perfil de Maria Gonçalves se restringia ao fato de que ela era conhecida pela alcunha de "Arde-lhe-o-rabo", além de ser "mulher vagabunda [...] [tendo] conta com o Diabo e com ele dormia e tratava". ${ }^{6}$ Violante Carneiro também disse que Maria Gonçalves era "mulher vagabunda", afirmando que as práticas diabólicas da

6 ANTT. TSO, IL, Processo n. ${ }^{\circ}$ 10478, de Maria Gonçalves, 1591-1593, fl. 11 
acusada ocorriam mediante a oferta de parte de seu corpo em troca de "certas coisas para fazer feitiços".7 No entanto, nenhumas delas se dispôs a contar para as autoridades acerca do modo como vivenciavam as suas relações sexuais a partir do contato com o sobrenatural.

Assim, pode-se afirmar que Violante e Margarida Carneiro talvez soubessem das notícias vindas da casa onde Heitor Furtado de Mendonça se estabeleceu em Salvador, mais especificamente a respeito do fato de que ambas seriam presas e processadas no decorrer da visitação. Dessa forma, por estarem cientes, quem sabe tenham comparecido diante das autoridades da visitação a fim de denunciar Maria Gonçalves em razão de supostas feitiçarias: "os que atendiam à convocação do visitador, apressando-se a delatar erros alheios ou confessar os próprios, eram movidos por algumas espécies de medo" (VAINFAS, 2010, p. 291). O medo, no caso de Violante e Margarida, pode ser justificado pela iminência de serem denunciadas ou processadas, sendo fundamental, portanto, "mostrar serviço à Inquisição" (VAINFAS, 2010, p. 291).

Por essa perspectiva, é discutivel a hipótese de que ambas tenha comparecido perante o visitador, sob a função de denunciantes, sem terem considerado a possibilidade de também serem alvo das denúncias realizadas durante o periodo de permanência da comitiva inquisitorial na Bahia. Laura de Mello e Souza (1986, p. 397), por sinal, chega a recusar o fato de Violante Carneiro ter tomado conhecimento de quaisquer notícias acerca de uma delação contra ela ou de uma possivel prisão. Trata-se de uma afirmação problemática não somente pelos argumentos apontados acima, mas, também, por ser questionável desconsiderar que a acusada não tenha carregado consigo, ainda que somente após a afixação do Monitório, a culpa de ter se envolvido ilicitamente em relações amorosas com Cosmo Garção, Bernardo Pimentel, Álvaro Lobo Pereira, Bartolomeu de Vasconcelos e Simão de Mello. Por fim, é importante destacar a prisão da sua mãe no mesmo dia, 3 de janeiro de 1592, por conta de supostos delitos envolvendo o sobrenatural, incluindo, por exemplo, as mesmas práticas realizadas por Violante. De todo modo, em vez de se apresentar para confessar seus erros, mãe e filha acabaram por assumir o papel de denunciantes, de boas cristãs que zelavam pelo catolicismo dos outros. Estratégia, contudo, que não adquiriu sucesso.

Bernardo Pimentel, Cosmo Garção e Simão de Mello foram, em diferentes períodos da Visitação estabelecida na Capitania da Bahia, as testemunhas que denunciaram a sexualidade, a seu ver, desviante, de Violante Carneiro. Ao delatarem a cristã-velha, esses individuos compartilharam do mesmo entendimento hegemônico no período de quais papéis sociais as mulheres deveriam seguir, incluindo na vida sexual. Nesse sentido, compreenderam que a identidade por eles interpretada a respeito de Violante não correspondia às prescrições do periodo para as mulheres no âmbito moral e religioso.

Natural de Lisboa, Bernardo Pimentel era casado com Dona Custódia e morava no engenho de Matoim quando resolveu comparecer diante de Heitor Furtado de Mendonça, a fim de relatar um episódio ocorrido por volta de 15 anos, ainda na época em que era solteiro. Contou que, estando sob "conversação desonesta" com Violante Carneiro, a mesma teria lhe dito que conhecia uma forma de conquistar qualquer homem através das palavras da eucaristia: hoc est enim corpus meum. Violante não apenas the confidenciou essa prática, como, também, realizou o ritual com o próprio Bernardo Pimentel por duas vezes, "chegando a sua boca a dele denunciante"8. Ainda segundo o relato, "ela festejou muito com isso, mostrando que já o tinha preso com lhe ter dito as ditas palavras para se querer bem" 9

Passado um ano da denúncia acima, já em 1592, o cristão-velho Cosmo Garção também compareceu à mesa da visitação, denunciando Violante Carneiro por conta de um episódio se-

\footnotetext{
A denunciante chega a relatar que Maria Gonçalves oferecia um pedaço de carne de sua perna para efetivar a oferta. Cf. ANTT. TSO

IL, Processo n. ${ }^{\circ}$ 10478, de Maria Gonçalves, 1591-1593, fl. 13.

8 ANTT. TSO, IL, Processo n 12925, de Violante Carneiro, 1591-1594, fl. 04.

9 ANTT. TSO, IL, Processo n` 12925, de Violante Carneiro, 1591-1594, fl. 04.
} 
melhante ao ocorrido com Bernardo Pimentel. Por volta de sete anos, período em que estava casado com Gerônima de Barros, afirmou que tivera "amizade desonesta" com Violante e, durante o ato sexual, ela teria lhe dito "as palavras da consagração com que na missa se consagram a hóstia"10. Nesse caso, não houve confidência por parte de Violante a respeito do que significava o uso dessas palavras durante a prática sexual, tanto é que Cosmo Garção soube do que se tratava quando perguntou para outras pessoas acerca do seu significado. Não seria equivocado deduzir, portanto, que era recorrente o conhecimento sobre a eficácia do uso dessas palavras durante os atos sexuais, favorecendo o individuo que protagonizasse esses rituais mágico-religiosos.

O mesmo estranhamento esteve presente no relato de Simão de Mello, último denunciante. Por "alguns dias [e] por diferentes vezes", ${ }^{11}$ o denunciante estivera em "ato carnal" com Violante Carneiro, que, por sua vez, repetiu o mesmo ritual. Ao perceber a recorrência dessa prática, Simão questionou a cristã-velha e obteve, como resposta, o fato de que eram palavras utilizadas no momento da consagração eucarística. Com essa denúncia, conclui-se que a acusada não apenas conhecia essa prática há aproximadamente 15 anos, mas mantivera o uso da mesma com distintos parceiros durante esse tempo, já que o episódio citado por Simão de Mello remeteu ao período em que Heitor Furtado de Mendonça já se encontrava em Salvador.

O desfecho inicial desse processo resultou no entendimento dos religiosos de que Violante Carneiro se utilizou de "uma certa superstição indigna" no seio de "atos torpes e desonestos".12 Por isso, foi determinada a sua participação em um Auto-da-fé ${ }^{13}$ público, em que seria posta à porta da Sé de Salvador, portando uma vela acesa para, em seguida, ser degredada da Capitania de Salvador durante o periodo de quatro anos. Seu destino foi a llha de Itaparica, local em que deveria cumprir penitências espirituais também citadas na sentença. No contexto de um pedido feito pela própria a fim de que a pena do degredo fosse comutada pelas autoridades da visitação, sabe-se que Violante, além de ter condição financeira precária, encontrava-se doente e mãe de "filhos pequenos", não sendo possivel precisar o número exato. Diante do aceite do visitador, Violante Carneiro retornou à Bahia após 8 meses na dita ilha, sendo determinada a obrigação de comparecer periodicamente às missas e confessar-se, além de rezar o rosário de Nossa Senhora. A sua trajetória a partir da decisão publicada em 1594 deixou de ser registrada no âmbito do Santo Ofício.

A sua mãe, Margarida Carneiro Magalhães, também foi encarada pelas autoridades religiosas como exemplo de mulheres na Capitania da Bahia que fugiram dos limites impostos pelo catolicismo quanto à sexualidade. A mãe de Violante era natural do Cabo de Guer, também conhecido como Fortaleza de Santa Cruz do Cabo de Guer, erigida em 1505, pelo comerciante João Lopes de Siqueira, e repassada à Monarquia portuguesa no ano de 1513. Essa fortaleza estava inserida no contexto de ampliação da presença lusitana no norte da África. Destaca-se, ainda, a sua inserção nessa esfera expansionista portuguesa e nos inúmeros conflitos enfrentados pelos portugueses, na tentativa de manutenção da sua presença no continente. João Cosme (2010, p. 14), por exemplo, menciona os diversos cercos que as praças portuguesas sofreram nas primeiras décadas do século XVI, empreendidos muitas vezes pelo rei de Fez. A fortaleza de Santa Cruz do Cabo de Guer foi, por exemplo, cercada em 1511 pelos mouros vindos da região de Suz.

\footnotetext{
ANTT. TSO, IL, Processo n 12925, de Violante Carneiro, 1591-1594, fl. 07.

ANTT. TSO, IL, Processo n 12925, de Violante Carneiro, 1591-1594, fl. 08-09.

ANTT. TSO, IL, Processo n 12925, de Violante Carneiro, 1591-1594, fl. 16.

Segundo Bartolomé Benassar (1984, p. 178), o auto-da-fé foi o ápice da exposição do indivíduo diante da sociedade, vide a mácula social, além do controle da Inquisição para além da prisão e de uma série de limitações que o sentenciado vivenciava após a sua condenação. Em linhas gerais, o auto-da-fé pode ser compreendido como o "ritual maior da Inquisição e foi-se transformando no mais impressivo emblema da sua representação, assumido pela população como a própria imagem do Tribunal. Destinava-se à leitura das sentenças dos processos findos e reconciliação com a Igreja dos penitenciados considerados arrependidos, associando-se-lhe, em seguida e noutro espaço, a aplicação do castigo mais severo que poderia decorrer de decisão dos inquisidores: o relaxamento do réu à justiça secular. [...] E essa, para os hereges e apóstatas, era a morte pelo fogo [...]" (MARCOCCl; PAIVA, 2013, p. 263-264)
} 
Entretanto, nada se sabe a respeito do modo como Margarida Carneiro atravessou o Atlântico rumo à América portuguesa, se sua condição de viúva foi adquirida após essa travessia ou se Violante teria nascido antes ou após a sua chegada a Salvador. TalvezMargarida Carneiro tenha saído dessa fortaleza por conta de a mesma ter sido abandonada pelos portugueses a partir de 1541, cujo desfecho da saída da praça de Arzila ocorreu em 1550. Combinada ao próprio contexto da época, que encarava o Novo Mundo como "prolongamento modificado do imaginário europeu" (MELLO E SOUZA, 2009, p. 46), a necessidade de sair da fortaleza diante dos conflitos existentes pode ser considerada como a mais provável justificativa da chegada de Margarida à América.

Margarida Carneiro, viúva de Pero Rodrigues, já se encontrava novamente casada, dessa vez, com Manoel Fernandes Leitão, quando Heitor Furtado de Mendonça, por conta de duas denúncias realizadas contra a cristã-velha, estabeleceu um processo a fim de investigar as suas supostas relações ilicitas com o sobrenatural. Em resumo, o seu processo foi sustentado pelas denúncias realizadas por Gaspar de Góis e Diogo Gomes, que deram conta ao Visitador das relações sexuais que ambos os denunciantes realizaram com Margarida Carneiro. Essas relações, segundo os próprios, teriam sido acompanhadas de ritos mágico-religiosos de cunho amoroso. As palavras da liturgia católica, hoc est enim corpus meum, foram proferidas pela acusada a partir da mesma intenção presente nas atitudes de Violante Carneiro.

Diferentemente dos relatos envolvendo Violante, os atos que Margarida Carneiro teria praticado, envolvendo as palavras da consagração, estiveram circunscritos a um pequeno núcleo familiar. Isso porque Gaspar de Góis, Domingos Mendes - seu sogro - e Diogo Gomes, que tinha Gaspar de Góis como genro, foram os homens com os quais Margarida se envolveu sexualmente e utilizou o mesmo ritual realizado por sua filha.

Não foi possivel descobrir se o casamento com Maria de Sá já era vigente quando seu marido, Gaspar de Góis, esteve em "conversação desonesta" com Margarida Carneiro. Tampouco se sabe a respeito do primeiro casamento de Margarida com Pero Rodrigues, à época do episódio relatado pelo denunciante. O fato é que, por volta de 1583, ambos tiveram uma curta relação, na qual Margarida "chegando a sua boca a dele disse as palavras da sacra hoc est corpus meum"14. Complementou dizendo que "Domingos Mendes sogro dele denunciante que tendo também ajuntamento desonesto com ela, ela da mesma maneira lhe dizia as ditas palavras"15. A mesma Margarida teria oferecido ao denunciante uma "carta de tocar"16, que deveria ser utilizada em uma mulher, mameluca, chamada Vitória. A denúncia de Gaspar de Góis subentende que Vitória era o seu alvo amoroso e, por isso, teria recebido a tal "carta" como forma de conquistar sua atenção ${ }^{17}$. No entanto, para frustração de Gaspar, a dita Vitória acabou por se interessar por Manoel Fernandes Leitão que, posteriormente, se casou com Margarida.

Há a possibilidade de o denunciante ter compreendido que os atos de Margarida Carneiro não correspondiam a uma realidade prescrita pela Inquisição, a partir da afixação do Monitório realizada quando a Visitação chegou na Capitania da Bahia. Por sua vez, pode-se considerar que Diogo Gomes tenha comentado com Gaspar de Góis a respeito das práticas sexuais da cristã-velha, já que ela fizera o mesmo ritual com Diogo. Ademais, com este último, além de ter dito as tais palavras, lhe contara qual era a finalidade do ritual: "e lhe disse que com aquilo queriam bem os homens as mulheres"18.

Já no contexto das arguições realizadas pelas autoridades presentes, e seguindo a lógica inquisitorial, o delito não foi apresentado explicitamente

\footnotetext{
4 ANTT. TSO, IL, Processo no 10751, de Margarida Carneiro Magalhães, 1591-1592, fl. 03.

ANTT. TSO, IL, Processo no 10751, de Margarida Carneiro Magalhães, 1591-1592, fl. 03.

Segundo José Pedro Paiva (PAIVA, 1997, p. 118), "as 'cartas de tocar' eram papéis que se deviam usar junto do corpo, para através desse contacto the transmitirem as suas virtudes protectivas. O nome que se thes dava estava por certo ligado a esta ideia e ainda ao facto de que, quando eram usadas na magia amorosa, os seus possuidores deviam tocar com elas na mulher que pretendiam".

17 ANTT. TSO, IL, Processo no 10751, de Margarida Carneiro Magalhães, 1591-1592, fl. 03.

18 ANTT. TSO, IL, Processo no 10751, de Margarida Carneiro Magalhães, 1591-1592, fl. 05.
} 
pelos religiosos, sendo apenas perguntado à Margarida se a mesma conhecia quais eram as palavras utilizadas pelos padres durante a consagração litúrgica. Em resposta, Margarida confirmou o conhecimento dessas palavras, além de afirmar que tomou ciência desses dizeres durante o período em que residiu no mosteiro das órfãs, situado na fortaleza em que vivia. Questionada se teria utilizado essas palavras para condicionar as vontades de algumas pessoas, a mesma não titubeou em afirmar que as usou com seu então marido por conta da sua má vida conjugal, já que, pelo fato das "ditas palavras [...] serem sagradas amansaria ao dito seu marido para lhe querer bem".19

Fato é que, em 4 de janeiro de 1592, foi publicada a sentença determinando a participação de Margarida em um Auto-da-fé, promovido por Heitor Furtado de Mendonça, ao qual compareceu "descalça em corpo, sem saio, cingida com uma corda e assim esteja um domingo em pé na Sé enquanto se celebrar o oficio divino da missa, com uma vela acesa na mão". 20 Algumas penitências espirituais foram previstas, predominando as que possuiam maior relação com os desvios de fé da acusada, já que o desrespeito à sacralidade católica tinha sido a motivação de seu processo.

Chama a atenção o intrincado jogo de relações amorosas pertencente ao círculo social de Margarida Carneiro, como, por exemplo, a sua vida de casada e o interesse em sua manutenção através do diálogo com o sobrenatural. Na denúncia de Diogo Gomes, foi afirmado que as palavras da liturgia teriam sido faladas por Margarida quando ambos se relacionaram sexualmente já no periodo, destaca-se, em que a acusada se encontrava casada com Manoel Fernandes. Nesse mesmo episódio, a cristã-velha teria confidenciado ao denunciante que o intuito desse ritual, assim como no descrito durante o processo de Violante Carneiro, consistia em fazer com que os homens desejassem as mulheres. ${ }^{21}$ Independente da veracidade da sua afirmação, nota-se, a partir dos relatos iniciais de mãe e filha, que a sexualidade nesse periodo assumiu um papel importante nas relações interpessoais ali existentes ${ }^{22}$.

No caso específico de Violante, talvez o matrimônio não tenha sido a opção mais viável, muito por conta dos motivos financeiros, já que a cristã-velha não possuía grandes recursos no periodo. Além disso, há uma questão não tão visivel, embora acredite-se na viabilidade de apresentá-la, e que se refere à possibilidade de a acusada possuir uma desilusão frente ao casamento, visto que, mesmo sendo viúva, era permitido o reingresso nesse sacramento. Já à época de sua prisão, as autoridades constataram que Violante encontrava-se grávida, recaindo na figura do cônego da Sé de Salvador, Bartolomeu de Vasconcelos, a responsabilidade paterna. Com a documentação disponivel referente ao seu processo, não foi possivel identificar quaisquer indícios acerca da possibilidade de o religioso ter assumido publicamente algum compromisso com a cristã-velha, mesmo se apenas com relação à criança. Defende-se que esse possivel silêncio por parte do religioso não foi motivado pelo "amancebamento", conforme justificou Ronaldo Vainfas, mas por conta "de a moça ser useira em proferir as palavras da sacra na boca do amado" (2010, p. 292). Assim, seria desvantajoso, aos olhos do clérigo, assumir quaisquer laços com uma mulher cuja fama consistia na utilização indiscriminada do sobrenatural, ainda mais por se tratar de uma prática capaz de conferir à Violante uma posição de protagonismo no sexo. Por fim, outro argumento que sustenta essa desilusão amorosa consiste no fato de que a sua condição de viuvez já passava dos 18 anos. Se houvesse uma desilusão no campo do amor, em vez de ser uma atitude direcionada somente

\footnotetext{
ANTT. TSO, IL, Processo no 10751, de Margarida Carneiro Magalhães, 1591-1592, fl. 07.

"[...] aprenderá os mandamentos da lei de Deus e os mandamentos da madre santa Igreja, e os pecados mortais porque os não sabe dizer: e por tempo de um ano confessará as três festas principais, Natal, Páscoa, Espírito Santo, e nelas receberá o santíssimo sacramento de conselho de seu confessor [...]". Cf. ANTT. TSO, IL, Processo no 10751, de Margarida Carneiro Magalhães, 1591-1592, fl. 12.

21 ANTT. TSO, IL, Processo no 10751, de Margarida Carneiro Magalhães, 1591-1592, fl. 04.

22 Por isso, defende Anne Barstow (1999, p. 178), cabe ao pesquisador não apenas problematizar a relação entre a sexualidade das mulheres e as práticas interpretadas sob o conceito de "bruxaria", mas, principalmente, entender como as mulheres construiam e vivenciavam as suas sexualidades na Época Moderna.
} 
à via matrimonial, Violante não teria delimitado tamanha fluidez nas suas relações com outros homens após o falecimento do seu cônjuge.

Quando avaliadas as atitudes de Margarida Carneiro frente ao casamento, notam-se alguns posicionamentos distintos que foram tomados pela cristã-velha, ainda que tenha utilizado o mesmo aparato ritualístico de sua filha. Ou seja, acredita-se que Margarida optou por realizar os rituais citados a fim de viabilizar um novo casamento, já que era viúva de Pero Rodrigues, e não necessariamente como forma de ampliar as suas relações amorosas ou sexuais. $O$ fato de ter procurado os homens aqui citados, como Diogo Gomes ${ }^{23}$, já no período em que era viúva, também corrobora com essa conclusão. De forma até mais nítida que a apresentada no processo de Violante Carneiro, prevaleceu a manutenção da sacralidade nessas interações, resultando, inclusive, na reinserção de Margarida Carneiro no sacramento do matrimônio e, por consequência, na vida social que uma boa cristã, aos olhos da Igreja, deveria levar e tornar pública aos demais individuos. Pode-se concluir, portanto, que este sacramento foi almejado por Margarida Carneiro, além de ter sido elemento distintivo entre a forma como mãe e filha utilizaram de um mesmo ritual mágico-religioso voltado ao campo das relações interpessoais. De todo modo, vale sublinhar que a maneira como ambas performaram as suas sexualidades as aproximou, muito por conta de terem se utilizado do sagrado católico como importante ferramenta para a concretização dessas vivências.

Além do mais, diante das práticas sexuais levadas adiante por Violante e Margarida Carneiro Magalhães, defende-se a inevitabilidade de atrelar não somente a construção das suas identidades gênero às práticas eróticas presentes no mundo português, mas, também, às relações sociais construidas nesse espaço ao longo dos Quinhentos. Se, assim como pressupôs Cássio Rocha (2016, p. 118), os homens nessa época encararam o sexo "como forma pública de demons- tração do gênero masculino", é compreensivel o estranhamento dos denunciantes de Violante e Margarida Carneiro diante do protagonismo que ambas possuíram nos atos sexuais praticados por elas. Também é viável considerar que o ato da denúncia foi, no mínimo, resultado de um misto de motivação desses homens em relatar episódios que acreditavam pertencer à alçada inquisitorial, somado à possibilidade de terem questionado a sexualidade vivenciada por essas mulheres no âmbito das suas identidades de gênero.

É importante retomar o fato de que se trata de um posicionamento milenar a atitude conservadora da Igreja Católica frente ao sexo, no qual o sacramento do matrimônio foi construido como espaço essencial para a regulação da sexualidade dos homens e, mais ainda, das mulheres. Em contrapartida, este tabu não impediu a proliferação de diversas práticas cotidianas cuja sexualidade foi temática recorrente, tornando-se campo fértil de subversão dos individuos frente às normatizações religiosas e seculares. Em meio às diversas tentativas da Igreja em delimitar as fronteiras referentes às práticas sexuais, vale lembrar o recorrente interesse das autoridades em definir quais as funções sociais condiziam às mulheres - tanto é que o casamento foi alçado não apenas como um instrumento de normatização do sexo, mas, também, dos comportamentos femininos. A medicina, por sua vez, contribuiu consideravelmente para persistência dessa atmosfera como, por exemplo, no século XVI. Segundo Thomas Laqueur (2001, p. 170), o pênis foi interpretado como um verdadeiro "símbolo de status [...] cujo portador tinha certos direitos e privilégios". O falo aparece nesse contexto como condição sine qua non não apenas para contribuir no contexto de definição dos papéis sociais, mas também para legitimar as hierarquias que sustentaram as relações de gênero no periodo: "o corpo parecia ser o absoluto fundamento de todo os sistemas do gênero bipolar" (LAQUEUR, 2001, p. 170).

Diante dessas ponderações, defende-se que a

23 A denunciante afirmou que "haverá dez anos sendo ela [Margarida Carneiro] viúva estando com ele denunciante no ato carnal chegando a sua boca a dele, the disse nela as palavras da sacra, hoc est enim corpus meum, e lhe disse que com aquilo queriam bem os homens as mulheres". Cf. ANTT. TSO, IL, Processo n 10751, de Margarida Carneiro Magalhães, 1591-1592, fl. 05 
expressão da masculinidade para esses homens no mundo português não passava pela possibilidade de aceitar o protagonismo das mulheres em um campo em que os desejos masculinos eram entendidos como prioritários. Sendo assim, as identidades de gênero de Violante Carneiro e a sua mãe, interpretadas por seus denunciantes, foram lidas como heterodoxas, pois, ao terem utilizado as palavras da liturgia católica no âmbito dos atos sexuais que praticavam, ambas ingressaram no universo do "amor desonesto", conforme consta na sentença da filha de Margarida Carneiro.

Já a categoria mulher é aqui entendida como um processo, assim como proposto por Judith Butler (2016, p. 58-59). Essa concepção implica, por sua vez, em considerá-la como uma construção incapaz de possibilitar ao pesquisador identificar suas origens e, tampouco, o seu fim. Portanto, quando o foco reside em valorizar esse processo, em vez de resgatar a existência de uma suposta "feminilidade original ou genuína" (BUTLER, 2016, p. 58-59) - um mito das origens, segundo a autora -, é possivel afirmar, por exemplo, que tanto Violante Carneiro quanto sua mãe, Margarida, construíram os seus gêneros para além dos padrões pré-concebidos de feminilidade. Essas mulheres ressignificaram as estruturas do sexo e do catolicismo, embora estivessem inseridas em um contexto normativo voltado à regulação dos corpos, principalmente das mulheres. Diante de um período em que os interesses masculinos marcaram decisivamente a consolidação das interações amorosas em torno do casamento, sendo estas influenciadas por um olhar patriarcal, mãe e filha definiram suas sociabilidades a partir da autonomia frente a esse processo. Dessa forma, definiram a diferenciação de parceiros como característica das afinidades que possuíam e o protagonismo como condição essencial para as suas práticas sexuais. Nesse contexto, as suas sexualidades emergiram de modo mais fluido do que era imaginado e proposto pelos mais ortodoxos moralistas.

A "unidade do gênero" foi, portanto, ressignificada a partir da sexualidade vivenciada por Violante e Margarida Carneiro, visto que não era pressuposto pelos discursos religiosos e seculares à época a possibilidade de valorização do protagonismo das mulheres nos atos sexuais. Ademais, essa mesma ressignificação ocorreu por conta da sacralidade e dos usos do sobrenatural terem sido interpretadas como elementos essenciais para ambas as mulheres no âmbito das práticas sexuais que realizaram. Nesse sentido, pode-se afirmar que prevaleceu uma subversão possivel, na medida em que ambas se valeram de elementos pertencentes a um contexto normativo, incluindo a sacralidade católica, para romperem, ainda que relativamente, com esse próprio aparato discursivo responsável por negligenciar a sexualidade e os corpos femininos. Houve uma subversão a partir do momento em que a mesma ocorreu "dentro dos termos da lei, por meio das possibilidades que surgem quando ela se vira contra si mesma e gera metamorfoses inesperadas" (BUTLER, 2016, p. 164). Por essa razão, cabe igualmente refletir em que medida Violante Carneiro e Margarida Carneiro ultrapassaram completamente os limites da matriz sexo/desejo/gênero hegemônica no período, cuja função residia em conformar a identidade de gênero das mulheres aos ideais de submissão.

Ainda nos pressupostos defendidos por Butler (2016, p. 25), relativiza-se a possibilidade de ambas serem exemplos de mulheres que efetivaram uma completa libertação do "corpo culturalmente construido", tendo em vista o forte contexto de vigilância encabeçado, por exemplo, pela Inquisição portuguesa. Entretanto, desconsiderar simplesmente a busca por essa subversão seria uma nova forma de negligenciar as subjetividades femininas diante desse contexto, além de naturalizar a existência dessa estrutura normativa, condenando as mulheres à reprodução dos papéis sociais a elas prescritos. Sendo assim, as atitudes de mãe e filha não devem ser interpretadas como exemplos de uma completa ruptura com o catolicismo vigente. Embora seja possivel demarcar a distância das práticas mágico-religiosas dessas mulheres diante da ortodoxia pretendida por Igreja e Estados, os traços dessa transgressão foram eminentemente religiosos, 
na medida em que a liturgia foi a ferramenta utilizada para a consolidação de seus universos eróticos. Por outro lado, permanece a defesa da existência de uma série de subversões realizadas por essas mulheres frente aos pressupostos amplamente defendidos por instâncias religiosas e civis referentes ao processo de reafirmação das relações de poder e da manutenção dessa matriz. A sexualidade, largamente regulada por autoridades e intelectuais, adquiriu uma outra face e se tornou nociva ao próprio sistema, o qual buscava utilizá-la como exemplo da necessidade de manter um determinado arranjo referente aos comportamentos das mulheres, principalmente.

Os processos inquisitoriais realizados contra Violante Carneiro e Margarida Carneiro podem ser encarados, também, como exemplos que possibilitam ao pesquisador visualizar a luta entre as instituições de poder e os sujeitos históricos no contexto de controle e definição das subjetividades femininas, incluindo aí o modo como as mulheres devem compreender o sexo. Sendo assim, não bastaram os discursos, as erudições médicas, bem como a consolidação de mecanismos de vigilância quando, em meio a essa estrutura, emergiu uma série de práticas cotidianas discordantes, como as que foram levadas adiante por Violante e Margarida Carneiro. Em ambas as trajetórias, não apenas o tornar-se mulher esteve atrelado ao modo como mãe e filha entenderam suas sexualidades e o sobrenatural, mas, também, às formas como ambas optaram por construir as suas vidas no período em que viveram na Capitania da Bahia.

\section{Considerações finais}

Os processos analisados ao longo deste artigo são representativos de como as identidades de gênero associadas às mulheres feiticeiras e performatizadas por Violante Carneiro e Margarida Carneiro corroboram com a necessidade de compreender a "abordagem do gênero como uma construção cultural complexa" (BUTLER, 2016, p. 73). Nesse sentido, a opção em reunir essa documentação neste artigo esteve essencialmente sustentada pelo entendimento de que essas mulheres performatizaram suas identidades sob uma mesma base de atitudes, em que não somente o gênero, mas o gênero associado ao sobrenatural, foi estilizado frente a uma estrutura reguladora e heterossexual.

Esses processos também foram reunidos sob o intuito de reafirmar que essas identidades não devem ser interpretadas como um constructo externo aos sujeitos, ou seja, a mulher feiticeira não foi apenas uma identidade construida por quem conviveu com essas mulheres. Por essa razão, este trabalhou buscou valorizar a capacidade das próprias mulheres associadas ao delito da feitiçaria de terem construido os seus papéis de gênero, predominando seus os interesses por autonomia, mais precisamente em reafirmar o domínio sobre as suas próprias vontades, sobretudo em conjunturas pouco favoráveis a elas. Em momentos desfavoráveis, Violante Carneiro e Margarida Carneiro optaram pela utilização das práticas mágico-religiosas com a intenção de melhorarem suas próprias condições: o casamento e a fluidez na sexualidade.

Por outro lado, essas mesmas mulheres estiveram distantes das grandes famas que caracterizaram outras mulheres igualmente processadas pela Inquisição portuguesa ao longo do século $\mathrm{XVI}$. As análises referentes às práticas mágico-religiosas destacadas na documentação constataram que os rituais empreendidos estiveram circunscritos às demandas dessas próprias mulheres, em vez de terem atendido às solicitações de terceiros. Portanto, pode-se afirmar que as atitudes dessas duas mulheres constituem um indício da predominância de seus interesses em reorganizar as suas próprias vidas, antes mesmo de considerarem a publicidade social referente a essa capacidade de intervenção no sobrenatural. Através da sexualidade, Violante e Margarida Carneiro são exemplos de mulheres que assumiram protagonismo em um universo no qual a normatização heterossexual foi marcante, tendo em vista o interesse da Igreja em silenciar quaisquer autonomias das mulheres diante do sexo.

Por mais que sejam identificados os discursos sustentadores de uma unidade de gênero plausivel, 
as discussões referentes a esses dois processos também permitem afirmar que a mulher feiticeira compreendida por essas autoridades não correspondeu obrigatoriamente à identidade de gênero seguida por essas duas mulheres processadas.

O indício mais consistente que corrobora com esse argumento diz respeito à ausência majoritária do Diabo como motivação para o estabelecimento dos processos e, mais ainda, por conta das crenças e práticas narradas pelas próprias mulheres, ou mesmo por quem as denunciou. Nesse sentido, predominaram entre essas mulheres feiticeiras uma série de práticas que subverteram as expectativas de gênero direcionadas tanto ao que se esperava socialmente delas como mulheres, quanto do que foi comumente aceito entre inquisidores e autoridades seculares sobre a figura ideal da feiticeira. Esta constatação permite ao historiador compreender que a unidade do gênero constitui um efeito de práticas reguladoras interessadas não somente em definir o padrão de feminilidade, mas, também, em delimitar quais práticas seriam caracterizadas como subversivas e qual seria o perfil das mulheres que protagonizavam essas práticas. Em outras palavras, na medida em que pretendem uniformizar os gêneros e suas funções sociais, essas práticas reguladoras também estão preocupadas em delimitar quais atitudes pertencem ao campo da subversão para, justamente, construírem uma argumentação homogênea capaz de identificar e cercear essas práticas.

No entanto, os limites dessas regulações tornaram-se evidentes na medida em que as narrativas de cada processo foram destrinchadas e analisadas no âmbito da valorização das práticas de autonomia empreendidas por Violante e Margarida Carneiro. Essa evidência emergiu ainda que ambas estivessem inseridas em um amplo contexto normativo, cuja sexualidade, a religiosidade, enfim, os papéis direcionados às mulheres, foram amplamente produzidos e difundidos por uma estrutura heterossexual e compulsória. Ainda que as suas identidades de gênero não sejam exemplos de uma completa ruptura com essa estrutura, suas trajetórias indicam a possibilidade de compreender, não apenas no âmbito da His- tória, as subjetividades femininas para além da mera reprodução dos discursos vigentes.

\section{Referências}

DGA/TT. Tribunal do Santo Ofício, Inquisição de Lisboa, Processo no 10751. Processo de Margarida Carneiro Magalhães, 1591-1592.

DGA/TT. Tribunal do Santo Ofício, Inquisição de Lisboa, Processo no 12925. Processo de Violante Carneiro, 1591-1594

BARSTOW, Anne. On Studying Witchcraft as Women's Story. Historiography of the European Witch Persecutions. Journal of Feminist Studies in Religion, v. 4, n. 2, p. 7-19, 1988.

BARSTOW, Anne. La caza de brujas: história de um holocausto. Málaga: Tikal, 1999.

BELLINI, Ligia. A coisa obscura: mulher, sodomia e Inquisição no Brasil colonial. Salvador: EdUFBA, 1989.

BENNASSAR, Bartolomé. Modelos de la mentalidade inquisitorial: métodos de su "pedagogia del miedo". In: ALCALÁ, Ángel et al. Inquisición Espanola y mentalidad inquisitorial. Barcelona: Ariel, 1984.

BUTLER, Judith. Problemas de Gênero: feminismo e subversão da identidade. Trad. de Renato Aguiar. Rio de Janeiro: Civilização Brasileira, 2016.

COSME, João. Tratado de paz entre Portugal e o reino de Fez, Arzila, 8 de maio de 1538. Arquipélago: História, [S. l.], $2^{a}$ série, n. XIV - XV, p. 11-29, 2010.

FREYRE, Gilberto. Casa-Grande \& Senzala: formação da familia brasileira sob o regime da economia patriarcal. 51. ed. São Paulo: Global, 2006.

FURTADO, Júnia Ferreira. Chica da Silva e o contratador dos diamantes: o outro lado do mito. São Paulo: Companhia das Letras, 2003

LAQUEUR, Thomas. Inventando o sexo: corpo e gênero dos gregos a Freud. Trad. de Vera Whately. Rio de Janeiro: Relume Dumará, 2001.

MARCOCCI, Giuseppe; PAIVA, José Pedro. História da Inquisição portuguesa: 1536-1821. Lisboa: A esfera dos livros, 2013.

MELLO E SOUZA, Laura de. O Diabo e a Terra de Santa Cruz: feitiçaria e religiosidade popular no Brasil colonial. São Paulo: Companhia das Letras, 2009.

MOTT, Luiz. O sexo proibido: virgens, gays e escravos nas garras da Inquisição, Campinas: Papirus, 1988.

MOTT, Luiz. Bahia: Inquisição e Sociedade. Salvador: EdUFBA, 2010.

NORONHA, Tito de; CABRAL, António. Espelho de Casados pelo Doctor João de Barros. 2. ed. conforme a de 1540. Porto: Imprensa Portuguesa, 1624.

PAIVA, José Pedro. Bruxaria e superstição num pais sem "caça às bruxas": 1600-1774. Lisboa: Editorial Notícias, 1997. 
PINTO, Frei Heitor. Imagem da vida cristã (1563-1572). 2. ed. Lisboa: Livraria Sá da Costa, 1958.

$\mathrm{RICH}$, Adrienne. Heterossexualidade compulsória e existência lésbica. Bagoas - Estudos gays: gêneros e sexualidades, [S. l.], v. 4, n. 05, p. 17-44, nov. 2012.

ROCHA, Cássio Bruno de Araújo. Masculinidades e Inquisição: gênero e sexualidade na América portuguesa. Jundiai: Paco Editorial, 2016.

SCOTT, Joan Wallach. Gênero: uma categoria útil de análise histórica. Educação \& Realidade, Porto Alegre, v. 20, n. 2, p. 71-99, jul./dez. 1995.

VAINFAS, Ronaldo. Casamento, Amor e Desejo no Ocidente cristão. São Paulo: Editora Ática, 1986.

VAINFAS, Ronaldo. Trópico dos pecados: moral, sexualidade e Inquisição no Brasil. Rio de Janeiro: Civilização Brasileira, 2010.

\section{Marcus Vinicius Reis}

Doutor em História pelo Programa de Pós-Graduação em História pela Universidade Federal de Minas Gerais (UFMG), em Belo Horizonte, MG, Brasil. Professor de História Medieval e Moderna na Universidade Federal do Sul e Sudeste do Pará (UNIFESSPA), em Marabá, PA, Brasil. Doutorado sanduíche na Universidade de Lisboa, em Lisboa, Portugal. Mestre pelo Programa de Pós-Graduação em História Social da Universidade do Estado do Rio de Janeiro (UERJ/FFP), em São Gonçalo, RJ, Brasil. Graduado (Licenciatura e Bacharelado) em História pela Universidade Federal de Viçosa (UFV), em Viçosa, MG, Brasil.

\section{Endereço para correspondência}

Marcus Vinicius Reis

Rodovia Transamazônica, s/n.

Residencial Total Ville Itacaiunas. Torre 8, apto 406

Bairro Nova Marabá, 68507-765

Marabá, PA, Brasil 